of our erops and food stores will not be abandoned, as efforts on a lesser scale were abandoned in 1919. During the War of 1914-18, the most widely used specific against lice was a rather crude mixture called 'N.C.I. powder'. It is interesting to note that, according to Prof. P. A. Buxton's monograph published in $1939^{3}$, it was still on the active list.

The neglect of applied entomology except in times of crisis has cost us dearly enough; in this present War, but for the efforts of a group of administrators and men of science working in close concert, it might have cost us even more. In the United States, Government departments, university and research institutions and individual workers themselves have described the magnificent effort they have made in this field. In Great Britain, official reticence, if not secrecy, has delayed until now any reference to the equally great effort made by workers in many fields, administrative and technical; industrial and scientific. The co-ordination of that effort and the startlingly successful development of 'D.D.T.' was possible only under able and distinguished leadership, both in the military and in the eivil branches, and it is to be hoped that in due course that leadership may be acknowledged.

${ }^{1} J$. Econ. Entom., 3\%, No. 1, 125 (1944).

2 Farmer and Stockbreeder, 58, No, 2847, 688 (1944).

s"The Louse" (London: E. Arnold and Co., 1939).

\section{THE VISUAL EDUCATION CENTRE, EXETER}

\author{
BY G. PATRICK MEREDITH \\ University College of the South-West, Exeter
}

$\mathrm{V}$ SUAL education starts with certain raw material in the form of items of organized knowledge (usually in verbal form); converts it into visual matter (photograph, diagram, etc.); presents it through some visual medium (wall-mount, cinéprojector, etc.); and usually combines it with oral teaching-all to help the learner to learn more efficiently than by the latter alone. At every stage problems arise. The field is wide and there are many workers in it. At the Visual Education Centre at Exeter we are endeavouring to find solutions to these problems; at its recent research conference its possibilities of usefulness, both as a research institution and as a forum, were demonstrated. (The Museum has a very important function in visual education. I have made no attempt to deal with this as it is beyond the scope of my title.)

The problems fall naturally into three main groups, concerned with visual matter, visual media and visual methods, respectively. The distinction between matter and media is all-important. The matter may be pictures, diagrams, pictograms, maps, symbolic charts, mathematical graphs, etc. Any of these may be presented through any of the visual media, namely, wall-mount or text-book illustration, episcope projection, diascope projection through lantern slide or film-strip, and lastly ciné-projection (silent or sound). Moving matter (ciné-film), microscopic matter and stereoscopic matter are restricted, of course, to special forms of presentation.

Extravagant claims for some particular medium are often made by enthusiasts who forget that we cannot get more educational value out of any material than was put into it; hence the need for the closest collaboration between film producers and educationists. Thus our major problems are with the design and supply of visual matter. These are fundamental. Next comes a series of practical problems concerning the design and supply of apparatus; training in manipulation; maintenance and repair of equipment ; finance, etc. Thirdly, the use of these media has to be integrated into the work of the teacher and into the curriculum as a whole. All these problems require systematic investigation.

\section{Origin of the Centre}

The stages by which the Visual Education Centre came into existence were briefly as follows. In 1940 I began, as a lecturer in the Education Department of the University College of the South-West, to specialize in the study of visual aids; the experience of a dozen years of science teaching had convinced me of their value. Visual education was incorporated into the diploma course and I gave students a training both in the handling of visual media and in the design of visual matter. At the same time I became secretary of the Film Council of the SouthWest, a recently established committee for the encouragement of the cinematograph for both instruction and entertainment. The Council represents the local education authorities, the University College, the schools, the cinema trade, the Ministry of Information and the British Film Institute. The latter, together with the local education authorities and local subscriptions, finance the Film Council. The secretaryship, at first voluntary, came to be accepted as College work, thanks to the goodwill and foresight of Principal John Murray, and of Prof. S. H. Watkins of the Education Department. Other work had to be dropped and funds raised to appoint a substitute; the director of the British Film Institute was instrumental in obtaining grants from industrial concerns, and the position was consolidated by the establishment of a lectureship in visual educa. tion. Equipment was purchased, clerical and technical assistance provided, temporary huts appropriated, and last year a research assistant, Dr. Renée Marcousé (now assistant lecturer), was appointed.

The Centre is fully occupied in training students, providing teachers' courses, supplying advice and information, providing film shows and other visual demonstrations both in the College and outside, for schools, for the Forces, for civil defence and other national services, for adult education and so on. It now issues its own bulletin, approximately quarterly. It maintains a very wide circle of contacts in all branches of visual education. Recently problems of aeronautics and industry have been insistently raised, and the setting up of an industrial section is contemplated. All along, the Centre has paid its way by grants raised ad hoc, now running well into four figures.

One of the Film Council's earliest achievements was the establishment of a regional film library. Dartington Hall generously provided housing and personnel. The Ministry of Information substantially aided the new library by choosing this as a regional distributing centre for the whole south-west region. Much valuable experience has been gained in this way, and the five counties have been kept supplied with non-theatrical $16-\mathrm{mm}$. films for the last three years. 

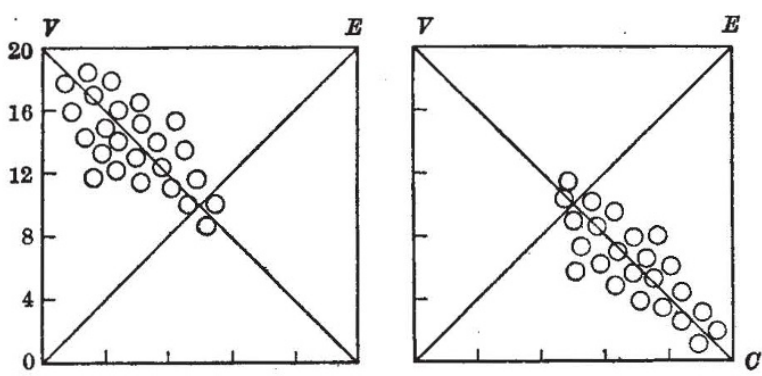

D
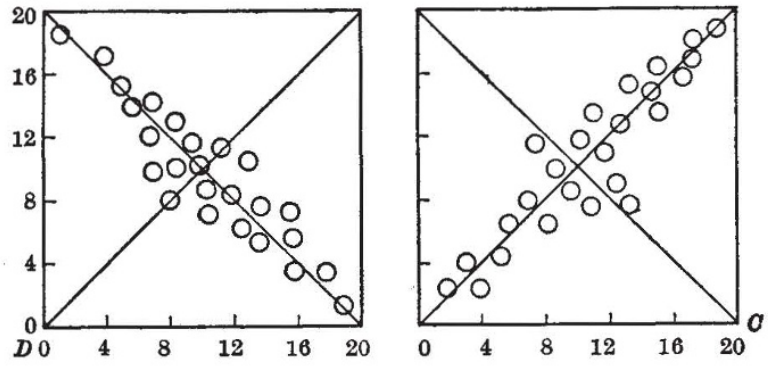

ASSESSMENT OF VISUAL MATERIAL BY TEST-SCORE ANALYSIS

The small circles represent individual test-questions. In any actual distribution they are numbered, and coloured according to type. Each has two coordinates $C$ and $V$, being the number of correct responses to the question given by the Control group and the Visual group respectively. (There were approximately twenty children in each group.)

The four distributions shown are some of the extreme distributions theoretically possible: 1 indicates a test favouring the visual group almost exclusively ; 2, Control group favoured; 3, approximately half the questions favour the Visual and half the Control group; 4, few questions discriminate between the two groups.

Obviously various statistical coefficients could be calculated from the data, but the main interest lies in the indications which the method provides of the detailed 'educational yield' of a particular piece of visual teaching.

$D E$ may be called the 'axis of difficulty', and $V C$ the 'visual-verbal axis'.

\section{An Experimental Inquiry}

Research, both experimental and theoretical, is the most important contribution a university centre can make. An investigation into visual teaching techniques has recently been completed in Exeter. The statistics are now being analysed, and a full report will be issued in due course. Owing to the inherent variability and multiplicity of the factors involved, the utmost caution is needed in interpreting the results of any educational experiment. A difference may be statistically significant, but the qualitative significance is often a matter of conjecture. A certain percentage difference ( \pm p.e.) between the average test-scores of two groups tells us very little. It is conceivable for two groups to have equal average scores and yet to have answered correctly two entirely different selections of questions. In the Exeter research particular attention was paid to the content and structure of the topics on one hand, and to the distribution of correct answers among the various test-questions on the other hand. The accompanying diagrams give four of the various theoretic- ally possible distributions, with their interpretations. The actual distributions, still being worked out, tend to be mixed in type, as would be expected.

The research seeks detailed information of two kinds. The first is an objective educational assessment of a particular 'graphic' (to borrow a useful term introduced by Lieut.-Commander Rawnsley, covering all forms of visual material) whether film, set of photographs, etc., or combination of these. Such information is essential if visual production is ever to work by methods other than rule-of-thumb. The second is a descriptive account of the practical problems which arise in the classroom in handling 'graphics', and the solutions adopted by a number of different teachers. A comparatively small-scale experiment, closely recorded, may yield more valuable information than a much larger experiment which swamps the desired information in arrays of averages. Four schools were used. There were two groups in each, a 'visual' and a 'control'. The teachers were supplied with detailed notes of the topics and with visual materials. Initial, final and delayed tests were given. They were objective 'new. type' tests. Four different topics were chosen and each was tried out in all four schools, but the visual method was slightly different in each case. The four methods were: film alone, static pictures alone, film plus static, and segmented film plus static. (The theory of 'segments' will be given presently.) The test-questions were sub-divided under four headings according as they dealt with problems, observations (raw facts), representations (grouped facts, that is, laws) or inferences (explanations and theories). The dots representing each question in the analysis charts are coloured according to these four headings. The distribution then shows at a glance whether any one type of question is favoured by the visual or by the verbal method. This technique lends itself to considerable development, and promises to remove much of the subjectivity from judgments on educational materials and methods. Thus the research as a whole was not concerned with verifying any particular hypothesis but with creating techniques and obtaining valuable information.

Films often contain material which is essentially static. Such material is better presented in static form, the film medium being reserved for essentially kinetic aspects of the topic. The theory of 'segments' is that phases of growth, change, motion, etc., should be presented in short film-segments of, say, 1-3 minutes duration, for detailed study and for integration with static 'graphics'.

\section{Discussion of Results}

The idea of research conferences is a sound one in a field where variation and multiple causation are the order of the day. The suspicion of statistics per se is a healthy one, but statistics submitted to a competent body of critics may yield very useful interpretations. A conference was held at Exeter during July 1 and 2 with personnel from the Board of Education, the local education authorities, the museums, the British Film Institute, the participating schools, Film Centre, Shell Film Unit, Common Ground, Ltd., Dartington Hall Film Unit, the Film Council of the South-West and the University College of the South-West. In the opening session the plan of the research was described and the "Exeter technique of visual assessment" explained by myself with coloured charts. Dr. Marcousé then gave an account of her systematic observations of the 
teaching procedure and of the overt responses of the children to the visual material. (In the full report this will be given in detail.)

Next came the teachers. All four schools had shown a most gratifying willingness to co-operate. Perhaps the most interesting feature of their testimony was the unlooked-for result that, quite apart from the stimulus to the children, the use of these visual techniques had a distinctly stimulating effect on the teachers. The extremely cordial relationship between the teachers, the Visual Education Centre staff and the director of education, Mr. G. A. Tue, was the sine qua non of the whole research. The four Exeter schools taking part were the two Episcopal Senior and the two Ladysmith Senior schools.

The lesson notes, tests and visual materials were all on view. The latter consisted of four films and still material consisting of large photographs of high quality, well-mounted, bearing full captions, and covering the four topics. Other material was also demonstrated.

Discussion took place on classroom techniques, on the use of museum material and on the planning of educational films. Miss Grayson (of the British Film Institute) stressed the need for co-ordination. The problem of making museum resources available for the schools was discussed. Mr. Neilson Baxter (Shell Film Unit) pointed to the valuable experience gained by many ciné-technicians in the production of instructional films during the War. Mr. Anstey (Film Centre) urged the setting up of a Government films department. The present author pointed out that if producers would plan educational films in series, each series following a characteristic treatment, a prototype film for each series could ke made and tried out by the Exeter technique. The evidence so obtained would provide guidance for the rest of the series. The conference was summed up by $\mathrm{Mr}$. K. de B. Codrington (Victoria and Albert Museum), who stressed the simple common elements which run through all good teaching and the need for using each type of visual material for the purpose to which it is most suited.

\section{General Conclusions}

Whatever researches are made on problems of media and methods, the fundamental problems are those of visual matter. Any visual production rests on a whole series of assumptions, conventions and decisions. No amount of technical or rsthetic virtuosity can compensate for a failure to come to terms with the philosophy of eurriculum-building or the psychology of the child. One important factor often neglected is the contribution of intellectua security to emotional stability. Our existing curricula present children with an anarchic sequence of incommensurable and unintegrated approaches to knowledge. If visual education neglects its fundamentals, it may easily perpetuate this state of affairs. Theoretical research at the Visual Education Centre is therefore concerned with the bearing of three normative disciplines on visual production, namely, logic, semantics and statistical theory. Visual productions must be consistent, they must present their meaning clearly, and they must take account of the variability which all objects display. This is a long story, to be presented in a larger publication, together with an account of its bearing on the curriculum as a whole, and the significance of these new developments in relation to the teacher's function and to national (and international) educational needs.

\section{MATHEMATICS FOR PHYSICISTS}

" AATHEMATICAL teaching," said Klein, "is a $1 \sqrt{ }$ function of two variables, the subject and the pupil." In other words, it is necessary to vary the presentation of the subject to suit minds of different types. Nineteenth-century physicists, such as Kelvin and Maxwell, started as mathematicians, and many of the contemporary mathematicians relied upon physical intuition, so at that time a common course of training was possible. The interests of the two parties have now diverged. The pure mathematicians have recognized that intuition may be successful for a long time, and yet lead in the end to a terrible blunder. They now keep to the straight and narrow path of rigorous logic. For example, they do not, like Fourier, assert that any function whatever can be expanded in an infinite series of harmonic terms, but occupy themselves with the difficult task of formulat. ing the precise conditions necessary and sufficient for this expansion.

On the other hand, experimental physicists regard mathematics as a tool, to be used whenever it is convenient to supplement the results of experiment, or as a language in which these results can be concisely expressed. To them Fourier's theorem is merely the mathematical form of a general physical principle, firmly established by experience. Why should they worry about possible exceptions which may never happen ? They prefer vigour to mathematical rigour, which seems to them as devoid of live interest as rigor mortis. Even if they could appreciate the need for the purely logical discussion, they would not have time to study it. What has been said of Fourier's theorem applies also to the large amount of advanced mathematics which is inseparably connected with recent advances in physics. The traditional 'mathematics subsidiary to physics' is now quite inadequate, but experimental physicists cannot afford the time needed for a great extension of the mathematical course on its present lines.

To deal with this dilemma, the Institute of Physics and the Mathematical Association have held a conference and issued a joint report, "The Teaching of Mathematics to Physicists" (Institute of Physics, Spencer House, South Place, London, E.C.2). They recommend courses much wider in scope but simpler in technique than the usual subsidiary mathematics. For example, their Schedule A, which is to cover the minimum requirements of a fully trained physicist, includes roughly the contents of both the two subsidiary subjects pure mathematics and applied mathematics (which are alternative subjects at some universities, such as London), with the addition of a little statistics. This doubled syllabus is to be covered in the same time as before, say, one third of the physicist's total study hours for two years. This is to be made possible by omitting the solution of difficult problems, and merely requiring the student to recognize the applicability of the mathematics to physics. Specimen examination questions are given to show how this can be done.

The report also gives a Schedule $\mathrm{B}$, suitable for the ablest undergraduates in their third year, and a Schedule $\mathrm{C}$ suitable for the postgraduate stage. At first sight these later schedules seem far beyond the capacity of any experimental physicist; but, as in Schedule A, it is intended that they should be treated with the minimum of technique. It is admitted that this will require special lectures and an increase in university staffs. It is suggested that such lectures 